\title{
Significado da profissão para alunos que ingressam na graduação em Enfermagem
}

\author{
The meaning of the profession to students beginning a Nursing undergraduate course \\ Significado de la profesión para estudiantes que ingresan al curso de Enfermería
}

\section{Thelma Spindola', Maria Madalena de Andrade Santiago', Elizabeth Rose da Costa Martins', Marcio Tadeu Ribeiro Francisco'}

\author{
' Universidade do Estado do Rio de Janeiro, Faculdade de Enfermagem, \\ Departamento de Fundamentos de Enfermagem. Rio de Janeiro-RJ, Brasil.
}

Submissão: 19/1/2010 Revisão: 7/11/2010 Aprovação: 10/8/2011

\begin{abstract}
RESUMO
Estudo qualitativo que objetivou descrever o significado da profissão para estudantes do primeiro período do curso de graduação em Enfermagem. Um roteiro estruturado foi aplicado a 33 alunos de uma universidade pública do Rio de Janeiro, em 2006. Todos os princípios éticos foram respeitados. A análise temática das descrições revelou que, ao ingressar na profissão, o discente percebe o enfermeiro como o profissional que cuida dos clientes, numa visão restrita ao cuidado assistencial, e associa sua prática a situações de dedicação, cuidado e amor. Esclarecer estudantes do nível médio sobre a Enfermagem, o mercado de trabalho e as áreas de atuação do enfermeiro poderia estimular a busca pela profissão de pessoas conscientes quanto a sua opção.
\end{abstract}

Descritores: Enfermagem; Estudantes; Educação Superior; Pesquisa qualitativa.

\section{ABSTRACT}

This qualitative study aimed to describe the meaning of the profession to beginners in a Nursing undergraduate course. A structured interview was administered to 33 students of the first semester in a public university in Rio de Janeiro, in 2006. Ethical principles were respected. The thematic analysis revealed that, when entering the profession, the students visualize nurses as the professional who takes care of clients, in a restricted view of care, and associate Nursing practice to situations of dedication, care and love. Clarify high school students about Nursing, the labor market and Nursing areas of action could stimulate the search of the profession by people more conscious about their choice.

Key words: Nursing; Students; Higher education; Qualitative research.

\section{RESUMEN}

Estudio cualitativo con objetivo de describir el significado de la profesión para los estudiantes del primero período de Facultad de Enfermería. Una entrevista estructurada fue aplicada a 33 estudiantes de Enfermería del primero período de una universidad pública de Río de Janeiro en 2006, respetando los principios éticos. El análisis temático verificó que, al ingresar en la profesión, el estudiante visualiza la enfermera como el profesional que se ocupa de los clientes, tiene una visión restricta al cuidado asistencial y el asocia su práctica a las situaciones de dedicación, atención y amor. Clarificar a estudiantes del nivel medio en el oficio de enfermera, el mercado del trabajo y las áreas del funcionamiento de la enfermera podría estimular la búsqueda de la profesión por personas conscientes cuánto a su opción.

Palabras clave: Enfermería; Estudiantes; Educación Superior; Investigación Cualitativa. 


\section{CONSIDERAÇÕES INICIAIS}

A Enfermagem pode ser definida como ciência humana, de pessoas com campo de conhecimento, fundamentações e práticas do cuidar dos seres humanos que abrangem as áreas de saúde e doenças. As ações de Enfermagem ocorrem através de relacionamentos pessoais, profissionais, científicos, estéticos, éticos e políticos ${ }^{(1)}$. O cuidado na Enfermagem compreende a pessoa sadia ou doente, em sua integralidade, considerando as dimensões familiar, comunitária e social em que ocorre a sua existência. Cabe ao enfermeiro a responsabilidade de ensinar, orientar e assistir as pessoas na promoção, prevenção, recuperação e reabilitação da saúde.

A dimensão do cuidado de Enfermagem visa alcançar a saúde numa inter-relação sujeito-sujeito, proporcionando conforto e bem-estar físico, mental e social e, portanto, deve contemplar a pessoa de forma integral. Entendida como cuidado profissional de Enfermagem, a ação de cuidar caracteriza-se por ser uma dimensão técnica, organizada e sistematizada, porém permeada pela subjetividade da relação enfermeiro-paciente, deixando de ser somente uma ação prática, fria e racional. O cuidado, que constitui a essência da Enfermagem, deve agregar diferentes atitudes do profissional em relação ao paciente, como ajuda, respeito, amor, atenção e compreensão mútua ${ }^{(2)}$.

A Enfermagem, nas últimas décadas, expandiu de maneira significativa seu campo de atuação e o mercado de trabalho para seus profissionais. Embora tenha evoluído expressivamente com a criação, em todas as regiões do país, de diversos cursos de mestrado e doutorado, e sua prática seja vital para as instituições de saúde, a profissão ainda é pouco valorizada.

No cotidiano do ensino com alunos da graduação em Enfermagem percebemos, com frequência, a indefinição dos jovens em relação à escolha feita. Ao ingressarem no curso superior e, especialmente, na Enfermagem, muitos estudantes desconhecem a profissão e se sentem inseguros quanto ao seu futuro profissional.

Em pesquisa sobre a temática, realizada nos acervos eletrônicos da Biblioteca Virtual em Saúde, que abarca produções nacionais e internacionais, mediante o método associativo dos descritores "graduação em Enfermagem" and "escolha profissional" or "estudante", encontrou-se 420 estudos, dos quais foram selecionados 9 associados ao assunto, sendo 1 tese de 1995, 1 monografia de 1988 e 7 artigos no período de 1988-2009, na base de dados Lilacs. Nesta busca destacou-se estudo que analisou a escolha profissional de alunos ingressantes nos cursos de Enfermagem, Nutrição e Fisioterapia, sendo observado que a escolha dos estudantes estava vinculada à imagem social da área e à influência familiar ${ }^{(3)}$. Os autores afirmam que, durante a formação, os estudantes ou reafirmam suas escolhas ou se definem por novas opções profissionais, sendo importante que a formação dos profissionais de saúde esteja articulada às políticas públicas que ampliam a participação de diferentes profissões.

Autores $^{(4)}$ investigaram alunos ingressantes na Enfermagem em duas instituições de ensino, pública e privada, comparando o perfil socioeconômico e fatores que interferem em sua opção profissional, tendo constatado que o mercado de trabalho em expansão e a oportunidade de uma remuneração melhor são fatores que atraem o estudante da instituição privada. A profissão e o campo de atuação do enfermeiro são desconhecidos pela maioria dos alunos da instituição públi$\mathrm{ca}$, que associam a imagem do profissional à pessoa que ajuda ao próximo. No mesmo enfoque, pesquisa ${ }^{(5)}$ delineou o perfil dos alunos ingressantes na graduação em Enfermagem da EEUSP em 2003, buscando as semelhanças e diferenças entre os alunos de três décadas anteriores, constatando que os alunos buscam a realização profissional e seguem idealistas, optam pela Enfermagem pelo desejo de ajudar as pessoas identificando-se com os ideais da profissão do enfermeiro.

A percepção dos graduandos de Enfermagem do primeiro ano do curso sobre a profissão foi discutida em estudo(6), observando-se que os estudantes iniciam o curso com a visão de que ser enfermeiro é gerenciar os serviços de Enfermagem, sendo capaz de cuidar, ajudar, manter e promover a saúde da população. Os motivos que fizeram os alunos buscar a Enfermagem foi gostar da profissão e para aumentar o conhecimento técnico-científico, considerando aspectos positivos os vários campos de atuação do enfermeiro e a colaboração com a cura; e, como aspectos negativos, os baixos salários e lidar com a morte. Os motivos que levam técnicos e auxiliares de Enfermagem a buscar a graduação na profissão foram discutidos em investigação ${ }^{(7)}$, evidenciando-se que estes percebem o curso superior como meio de crescimento pessoal, profissional e para a busca de conhecimento. A experiência prévia na Enfermagem atua como um elemento facilitador na aprendizagem.

Ao modificarmos os descritores para "profissão enfermeiro" and "aluno" or "escolha", localizamos 898 trabalhos. Destes selecionamos 24 associados à temática, entretanto 09 trabalhos estavam repetidos na base de dados. Todos, com exceção dos trabalhos repetidos, eram artigos publicados em periódicos nacionais e internacionais no período de 1989 a 2010. Nesta seleção destacamos estudo ${ }^{(8)}$ que buscou compreender as representações de alunos do ensino médio acerca da Enfermagem e do enfermeiro, sendo observadas representações de pouca valorização, o desconhecimento da formação educacional, dos campos de atuação, das possibilidades da profissão e de sua autonomia. No mesmo enfoque, autores ${ }^{(9)}$ relataram sua experiência em atividade de extensão junto a estudantes do ensino médio, em que divulgam a profissão do enfermeiro e suas competências em escolas públicas no Rio de Janeiro. Os pesquisadores observam a carência de informações sobre a Enfermagem e destacam a importância de suas ações para o esclarecimento dos jovens e incentivar a opção pela carreira.

Investigando adolescentes do ensino médio de uma escola pública, pesquisadores ${ }^{(10)}$ analisaram seus pré-juízos e estereótipos negativos em relação à profissão, constatando a baixa incidência destes no grupo investigado. Concluem que a informação correta é eficiente na redução de pré-juízos e estereótipos negativos, sendo este tipo de trabalho válido como veículo de divulgação da profissão. Estudo ${ }^{(11)}$ que descreveu a visão dos alunos do ensino médio sobre a Enfermagem e 
analisou sua percepção em relação às competências do enfermeiro constatou que o aluno associa a figura do enfermeiro à função assistencial, visualizando-o como auxiliar do médico, desconhecem as categorias profissionais da Enfermagem e o nível de escolaridade do enfermeiro. Destacam a importância de ações para uma maior divulgação da Enfermagem com objetivo de esclarecimento dos jovens.

Investigando jovens que ingressaram no curso de Enfermagem de uma instituição pública, pesquisadores ${ }^{(12)}$ constatam que a motivação para a escolha da Enfermagem está vinculada ao interesse em ingressar na área de saúde, a influência de familiares e o fértil mercado de trabalho. Concluem que os estudantes detêm pouco conhecimento sobre a profissão. No mesmo enfoque, estudo ${ }^{(13)}$ analisou a percepção dos alunos ingressantes na Enfermagem acerca dos regimes de verdade que perpassam a profissão, evidenciando concepções sociais que são atravessadas por saberes invisíveis que legitimam as práticas de saúde e de Enfermagem, tornando-as inquestionáveis. A visibilidade da profissão do enfermeiro/Enfermagem junto aos acadêmicos de Enfermagem foi analisada em pesquisa ${ }^{(14)}$, sendo observado que os estudantes percebem o enfermeiro como um profissional voltado para o cuidado, sentem orgulho da profissão que escolheram e têm consciência da capacidade e do potencial do enfermeiro. A visibilidade do enfermeiro, afirmam os autores, é conquistada nos diferentes espaços e campos de atuação da Enfermagem e vem se firmando como uma profissão em crescimento.

Analisando a percepção dos estudantes do ciclo básico da graduação de Enfermagem sobre o que é ser enfermeiro, autores ${ }^{(15)}$ percebem que os estudantes têm dificuldades em elaborar um conceito fundamentado sobre a profissão e destacam a importância de os alunos conhecerem melhor a Enfermagem e serem conscientizados do papel que desempenharão na estrutura social e multidisciplinar preservando sua autonomia.

Pesquisa ${ }^{(12)}$ com estudantes recém ingressados na graduação em Enfermagem estimulou uma das autoras a realizar atividade de extensão, com o intuito de divulgar a profissão de Enfermagem e o fazer dos enfermeiros para alunos do ensino médio no município do Rio de Janeiro. O projeto "Afinal o que é ser enfermeiro? Falando de nós para vocês", da Faculdade de Enfermagem da Universidade do Estado do Rio de Janeiro (FE/UERJ), iniciado em 2000, foi posteriormente ampliado para orientação dos acadêmicos que ingressavam no curso de Enfermagem da UERJ. O convívio com os estudantes da graduação em Enfermagem e a constatação da insuficiência de informações acerca da profissão e da prática profissional estimulou a realização deste estudo, tendo como questões norteadoras: $\mathrm{O}$ que motiva o aluno a buscar a Enfermagem como profissão? O que significa a Enfermagem para o aluno que faz esta opção profissional?

Em nossa observação empírica pudemos constatar que, para muitos destes estudantes, a opção pela Enfermagem resultou de fracassos anteriores nos vestibulares para a carreira desejada, em geral, a Medicina. Enfermagem, como outras profissões da área de saúde, torna-se, então, atraente àqueles que não conseguiram ser admitidos no curso escolhido, optando consequentemente, por áreas afins, ainda que desconhecidas.
Face ao exposto, consideramos relevante a realização desta investigação que pretende descrever o significado da Enfermagem para os estudantes que iniciam o primeiro período do curso, desvelando suas crenças e expectativas.

\section{METODOLOGIA}

A presente pesquisa caracteriza-se por ser um estudo descritivo com abordagem qualitativa. Justifica-se esta seleção pela possibilidade de narrar um acontecimento, apoiada nos aspectos dinâmicos, holísticos e individuais dos fenômenos $^{(16)}$, visto pretendermos esclarecer os significados que interferem no processo de construção da imagem do que é ser enfermeiro e, assim, compreender aspectos subjetivos associados ao imaginário da profissão.

O local escolhido para realização desta pesquisa foi a Faculdade de Enfermagem da Universidade do Estado do Rio de Janeiro, situada no bairro de Vila Isabel, município do Rio de Janeiro. O projeto foi apreciado e aprovado pelo Comitê de Ética do Hospital Universitário Pedro Ernesto, da Universidade do Estado do Rio de Janeiro, sob o número $1200 / 2005$. Os sujeitos do estudo foram trinta e três alunos do primeiro período do Curso de Graduação, da referida instituição. O critério de inclusão consistiu em ser estudante regularmente matriculado no $1^{\circ}$ período da Graduação em Enfermagem tendo ingressado no $1^{\circ}$ ou $2^{\circ}$ semestre letivo, sendo excluídos os discentes dos demais períodos da graduação. Foi realizado um sorteio aleatório de 33 estudantes matriculados no primeiro período, sendo facultada a participação dos mesmos. Os alunos foram informados em relação à não obrigatoriedade, ao anonimato e à inexistência de vínculo entre a investigação e qualquer atividade de ensino desenvolvida na Faculdade. Respeitando-se a Resolução 196/96 do Conselho Nacional de Saúde, aqueles interessados em participar do estudo assinaram o Termo de Consentimento Livre e Esclarecido.

$\mathrm{O}$ instrumento de coleta de dados foi um roteiro estruturado contendo quatorze questões, das quais cinco (5) abertas e nove (9) fechadas. A coleta de dados, realizada por um aluno bolsista de extensão, devidamente treinado, ocorreu durante o mês de março de 2006 numa das salas de aula da Faculdade de Enfermagem.

Para a análise dos resultados utilizamos a técnica de análise de conteúdo, na modalidade de análise temática. Esta técnica se desdobra em etapas sucessivas, iniciando-se com leitura, seguida da determinação das unidades de registro e significações, codificação e classificação. Por fim, o tratamento e interpretação dos resultados obtidos ${ }^{(17)}$. Assim, através de uma leitura flutuante dos instrumentos, procedemos às marcações das unidades de registro organizando-as por temas. A seguir, por aproximações e distanciamento dos temas foi-se construindo as categorias e subcategorias ${ }^{(17)}$.

\section{RESULTADOS}

No processo de análise dos achados emergiram duas categorias, a saber: 1) A imagem do enfermeiro, o profissional que 
cuida da saúde; 2) As atividades realizadas pelo enfermeiro e a ausência de autonomia.

Na categoria 1 é apresentado como os estudantes visualizam o enfermeiro e a Enfermagem exteriorizando suas opiniões acerca do profissional, suas características e aspectos que mais os impressionam, desvelando o significado da profissão para eles. Aponta, também, o fazer do enfermeiro entendido como o profissional que presta cuidado aos clientes. A categoria 2 descreve a ótica dos estudantes em relação às atividades realizadas pelos enfermeiros no ambiente laboral e a ausência de autonomia do profissional.

\section{A imagem do enfermeiro, o profissional que cuida da saúde}

Em seus relatos os estudantes descrevem como percebem a imagem do enfermeiro, a profissão e características inerentes ao profissional, conforme os recortes das descrições a seguir clarificam:

É uma profissão que precisa de muito carinho para desempenhar, muita dedicação, é preciso respeitar o próximo e ter muita responsabilidade em suas ações. (E 13)

Uma pessoa que desenvolve um trabalho sério, com responsabilidade, e ao mesmo tempo humano. Que valoriza a vida, que respeita o outro, se coloca no seu lugar. (E 23)

Um ato de amor ao próximo, amor à vida. O enfermeiro dedica a sua atenção ao paciente, é uma pessoa que se entrega por inteiro. (E 24)

O enfermeiro é reconhecido como uma pessoa responsável, dedicada, que se preocupa com o outro, desenvolvendo um trabalho para a promoção da saúde dos pacientes e exercendo uma profissão que requer responsabilidade e despojamento. Nestas descrições podemos perceber que os estudantes elencam as características relacionadas ao perfil do enfermeiro como o amor ao próximo, carinho, respeito e responsabilidade. No imaginário dos jovens recém-admitidos na universidade ainda estão presentes aspectos que constituíram o estereótipo das enfermeiras precursoras da profissão, no período em que a Enfermagem era desenvolvida por religiosas e/ou leigos, com fim apenas curativo. Nos livros de história da Enfermagem há registro das características pessoais que eram necessárias para uma boa enfermeira, destacando-se a responsabilidade, confiança, honestidade, religião e devoção.

Em estudo com graduandos de Enfermagem, pesquisadores afirmam que os alunos reconhecem a Enfermagem como uma carreira que exige dos futuros profissionais certos atributos pessoais como: amor ao próximo, compreensão, solidariedade, afeto, dedicação e responsabilidade(12). O cuidar em Enfermagem envolve sentimentos e sensações que interagem em cada forma particular do cuidado de cada pessoa ${ }^{(1)}$; a emoção, portanto, é um aspecto presente na prestação de cuidado ao cliente realizado pelo enfermeiro. Por outro lado, autores afirmam que se verifica a permanência de "uma idealização da caridade no trabalho da enfermeira por meio da forte presença de mitos da profissão"(18).

Considerando que a mídia nem sempre favorece a profissão, ainda podemos observar representações arcaicas sobre a Enfermagem e a figura da enfermeira, evidenciando a cristalização de prejuízos e, consequentemente, preconceitos em relação à Enfermagem. A imagem profissional da enfermeira é descrita como uma rede de representações sociais da profissão relacionada às suas características e significados exclusivos, sendo influenciada pela história da Enfermagem $^{(19)}$. Assim, complementam os autores ${ }^{(19)}$, a figura da enfermeira é ainda permeada pelos conceitos e estereótipos auxiliados à função de auxiliar o médico e a falta de vida social pela dedicação à profissão. A imagem da enfermeira é identificada pela sociedade sendo composta por estereótipos e evidenciando o desconhecimento sobre a sua atuação ${ }^{(14)}$. A enfermeira é identificada com distorções e muitas vezes, a profissional é desvalorizada socialmente em função da imagem de que recebe uma baixa remuneração e está subordinada a outros profissionais ${ }^{(14)}$.

Discutindo as representações sociais sobre o enfermeiro e a Enfermagem por profissionais de comunicação, pesquisadores $^{(20)}$ observaram o desconhecimento dos campos de atuação, mercado de trabalho e categorização profissional da Enfermagem, a invisibilidade do enfermeiro perante a mídia e a sociedade, além da responsabilidade do próprio enfermeiro para a visibilidade e reconhecimento da profissão. Recomendam estratégias para a transformação deste cenário, incluindo a exposição da Enfermagem perante a mídia e, por meio da mídia, alcançar a população.

Nas descrições dos estudantes, o enfermeiro é o profissional que cuida da saúde. O cuidado de Enfermagem adquire o significado de uma prática realizada pelo enfermeiro que propicia a recuperação e reabilitação do paciente, sendo fundamental para seu restabelecimento.

O cuidado de Enfermagem representa aquilo que se refere à recuperação, reabilitação do doente ou prevenção de doenças. É, portanto essencial para a recuperação saúde das pessoas. (E 3)

Representa uma chance de reabilitação do individuo. A pessoa tem oportunidade de ser auxiliada e recuperar a sua saúde. (E 8)

[...] o cuidado de Enfermagem, para mim, busca a independência do paciente. Ele é capacitado para cuidar de sua saúde. (E 9)

Nos fragmentos dos relatos podemos perceber que os estudantes associam o cuidado dos pacientes à prática assistencial do enfermeiro, o que contribui para a recuperação, reabilitação, prevenção de doenças e, também, para o autocuidado dos pacientes. Os alunos associam as ações do enfermeiro à assistência dos pacientes, ou seja, a assistência individualizada e curativa. O cuidado é a essência do trabalho do enfermeiro lembra Florence Nightingale ao estabelecer as regras gerais da profissão para assistir aos enfermos ${ }^{(21)}$. O cuidado pode ser entendido 
como desvelo, solicitude e atenção de uma pessoa para com outra, é uma palavra abrangente e, na Enfermagem, encerra todas as dimensões do indivíduo ${ }^{(2)}$. O cuidado de Enfermagem é uma ação inerente ao enfermeiro e demais integrantes da equipe de Enfermagem, embora outros profissionais, pais e responsáveis possam alegar que também cuidam de outros seres humanos.

Ultimamente os profissionais de Enfermagem, particularmente os que atuam nas instituições de ensino, têm se empenhado em atribuir a prática do cuidado uma visão integral da pessoa com o intuito de valorizar o homem em toda sua complexidade nas distintas áreas de atuação, ou seja, no campo da saúde, ensino, pesquisa e extensão(22). A expressão "cuidar" é predominante nos discursos dos estudantes quando questionados sobre o que significa ser enfermeiro. Todavia, poucos acadêmicos procuraram definir o que seria este cuidar. Acreditamos, que o ato de cuidar "exige responsabilidade, sentimento, envolvimento e comprometimento pessoal, afetivo, social, moral e espiritual"(23). A Enfermagem, como prática social, é um trabalho necessário e de interesse para a sociedade exercida por enfermeiros, técnicos e auxiliares que praticam o cuidado de Enfermagem à pessoa no seu processo de saúde-doença ${ }^{(24)}$. Os estudantes de Enfermagem devem ser instrumentalizados para o desempenho do ato de cuidar com a inclusão de valores, desejos e compromisso com o cuidado e o conhecimento (23).

\section{As atividades realizadas pelo enfermeiro e a ausência de autonomia}

Nos relatos os estudantes descreveram como visualizam as atividades que o enfermeiro realiza em seu ambiente laboral, como a atividade assistencial e administrativa e, também, que correlacionam as ações do enfermeiro ao trabalho médico denotando falta de autonomia da profissão.

\section{Assistência}

A atuação do enfermeiro na equipe de saúde e a importância do seu papel na assistência aos enfermos são percebidas pelos estudantes num contexto de integralidade.

É um profissional que está inserido em uma equipe multiprofissional, que presta cuidados ao cliente com uma visão holística do mesmo, participando ativamente da assistência. (E1)

Cuida dos pacientes, no que se refere a cuidados médicos/ hospitalares. Auxilia para a recuperação dos pacientes. (E 5)

Tem a possibilidade de estar mais próximo do paciente e fazer com que o tratamento seja mais humanizado. Presta cuidado aos pacientes, assistindo-os diretamente. (E 10)

Nas descrições dos estudantes podemos observar que os jovens visualizam o enfermeiro como um profissional integrante da equipe de saúde, que participa ativamente da assistência ao cliente, tendo uma perspectiva de cuidado integral e humanizado. No imaginário dos jovens, o cuidado à pessoa enferma, com prestação de uma assistência direta, são atividades desenvolvidas pelo enfermeiro no seu ambiente laboral. Os jovens dos períodos iniciais da graduação associam as ações do enfermeiro à prática médica circunscrita aos aspectos curativos da esfera hospitalar, conforme menciona a descrição do estudante 5. Esta conotação pode ser associada à falta de informação dos jovens sobre a profissão do enfermeiro, como, também, à maior divulgação do trabalho médico na esfera hospitalar. Os estudantes, empiricamente, idealizam o enfermeiro como o profissional que cuida e permanece mais tempo próximo aos pacientes, com quem mantêm maior contato. A Enfermagem é uma profissão que presta assistência à saúde das pessoas, sendo um trabalho necessário e de interesse para a sociedade exercida por enfermeiros, técnicos e auxiliares de Enfermagem, “cujo produto final é o cuidado de Enfermagem à pessoa no seu processo saúde-doença"(24). O cuidado é a essência da Enfermagem e ultrapassa "os aspectos técnicos e biológicos, psicossociais e espirituais do individuo, família e comunidade, envolvendo a provisão de ajuda, atenção, respeito, amor e compreensão mútua"(2). Neste contexto, percebe-se, então, que o enfermeiro é o profissional do cuidado e sua prática acontece em diversos ambientes não sendo circunscrita ao espaço hospitalar, conforme apontam as descrições dos estudantes que não se reportam a outros cenários como o campo da saúde pública, onde certamente tiveram contato com profissionais de Enfermagem em visitas para imunização, e o da educação. Neste sentido, autores ${ }^{(8)}$ afirmam que "os adolescentes desconhecem a atuação do enfermeiro nas áreas de promoção, resolução e prevenção, recuperação da saúde e defesa pela qualidade de vida".

\section{Administração}

$\mathrm{Na}$ visão dos discentes o enfermeiro, em suas ações, desenvolve atividades relacionadas à administração do serviço.

Planeja, organiza, coordena a equipe de Enfermagem na assistência aos pacientes/ clientes. (E 3)

Coordena os auxiliares e técnicos de Enfermagem [...] é como um gerente [...]. (E 10)

Controla a medicação dos pacientes. Supervisiona as ações dos demais profissionais de Enfermagem. (E 13)

Gerencia, organiza e supervisiona as atividades da equipe de Enfermagem. (E 33)

Os estudantes do início da graduação identificam as ações do enfermeiro no ambiente laboral associando-as às atividades administrativas de controle, supervisão e coordenação dos demais integrantes da equipe de Enfermagem. O enfermeiro atua "como um gerente" sendo responsável pelo planejamento das ações de Enfermagem e equipe, o que denota a percepção dos estudantes da liderança exercida pelo profissional diante dos demais integrantes da Enfermagem.

Autoras discutindo as teorias administrativas e organização do trabalho e as influências no setor saúde e na Enfermagem afirmam que a Enfermagem no campo hospitalar é responsável pela 
gerencia das unidades assistenciais e possui uma linha interna de mando vertical, formalizada e legitimada nos modelos taylorista-fordista, com grande poder das enfermeiras sobre os técnicos e auxiliares de Enfermagem ${ }^{(25)}$. Acrescentam que a enfermeira gerencia o trabalho da equipe de Enfermagem com ênfase para o cumprimento de normas, rotinas e tarefas, reproduzindo o que a instituição e outros profissionais esperam e deixa, muitas vezes, de priorizar as necessidades do doente o que gera descontentamento e desmotivação nos trabalhadores de Enfermagem ${ }^{(25)}$.

Analisando a articulação entre as dimensões gerencial e assistencial no trabalho do enfermeiro, pesquisadoras afirmam que o processo de trabalho deste profissional apresenta duas dimensões complementares, a dimensão gerencial e a assistencial $^{(26)}$. Acrescentam, todavia, que existe dificuldade de articulação dos enfermeiros entre as dimensões havendo priorização de uma ou outra, sendo recomendado o gerenciamento do cuidado com foco nas necessidades de saúde do paciente e de integração do serviço ${ }^{(26)}$.

\section{Ausência de autonomia}

Na percepção dos estudantes o trabalho de Enfermagem está vinculado ao do médico, numa relação de ajuda ou subordinação, como podemos notar nas falas a seguir:

O enfermeiro é o profissional que auxilia o médico nos mais diversos procedimentos. (E 2)

Os profissionais de Enfermagem cuidam dos pacientes mediante orientação médica. (E 13)

O enfermeiro cuida dos doentes e cumpre ordens, principalmente do médico [...]. (E 20)

Nestes discursos notamos que na ótica do estudante de Enfermagem do primeiro período da graduação, o enfermeiro não tem autonomia para desenvolver suas atividades, sendo um profissional que "cuida e cumpre ordens", atuando como um "auxiliar" do médico, deixando transparecer um trabalho subordinado, pouco valorizado, aquele que é dependente de outro profissional para o desempenho de suas funções. Autores ${ }^{(8-9)}$, estudando a temática do trabalho do enfermeiro na visão dos alunos do ensino médio e de estudantes dos períodos iniciais da graduação em Enfermagem, observam que os jovens relacionam o trabalho do enfermeiro, exclusivamente, à esfera hospitalar, com a função de dar continuidade à terapêutica médica. A imagem dos estudantes acerca do trabalho do enfermeiro denota o desconhecimento em relação à profissão e atividades desenvolvidas pelas distintas categorias profissionais da Enfermagem, a invisibilidade do enfermeiro e a pouca valorização da profissão para a mídia e a sociedade.

Neste sentido, recomendam estudiosos ${ }^{(20)}$, a visibilidade da Enfermagem é de responsabilidade do enfermeiro informar, divulgar, realizar com competência e dar transparência às suas ações para conseguir o reconhecimento social que dizem desejar. A visibilidade do enfermeiro, portanto, é conquistada pelos profissionais nos diferentes espaços e campos de atuação ${ }^{(14)}$. Embora a desvalorização profissional na Enfermagem ainda seja vivenciada pelos enfermeiros para transformar esta realidade é essencial que os profissionais se responsabilizem por suas ações, enfrentem os desafios "procurando apropriar-se das suas competências, de modo a intervir de forma pró-ativa nas diferentes demandas sociais"(14).

Para desmistificar a imagem da Enfermagem como uma profissão submissa ensaio ${ }^{(27)}$ traz uma reflexão da história da profissão aos dias atuais, sendo observado que a assistência de Enfermagem hoje é desenvolvida com embasamento científico, de maneira sistematizada, ao contrário do início da profissão quando os cuidados aos doentes eram subsidiados pelo pensamento médico. A sistematização da assistência de Enfermagem é uma estratégia para aplicação da cientificidade de nossa prática e evolução da profissão, sendo "a única possibilidade de o enfermeiro atingir a sua autonomia profissional e constitui a essência de sua prática

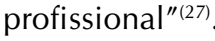

\section{CONSIDERAÇÕES FINAIS}

Este estudo teve o propósito de descrever o significado da Enfermagem para os estudantes do primeiro período do curso de graduação numa universidade pública estadual no Rio de Janeiro.

A análise das descrições revelou que os estudantes percebem a Enfermagem como uma profissão que requer do profissional carinho e amor ao próximo. Visualizam o enfermeiro como um profissional que cuida da saúde e associam à sua imagem a de uma pessoa dedicada, que se preocupa com o outro e desenvolve seu trabalho com responsabilidade e despojamento. O cuidado de Enfermagem é entendido como uma prática realizada pelo enfermeiro assumindo um papel fundamental na recuperação e reabilitação dos pacientes, numa perspectiva de integralidade e humanização da assistência. Os estudantes acreditam que a prática do enfermeiro está relacionada às atividades de assistência e administração, e suas ações estão vinculadas à prática médica denotando falta de autonomia da profissão.

Conhecer o significado da profissão para os estudantes que ingressam na graduação em Enfermagem permitiu-nos uma aproximação ao objeto de estudo sem, contudo, modificar resultados de pesquisas anteriores, considerando que nos tempos atuais os estudantes ainda ingressam na graduação com pouca informação sobre a Enfermagem.

Acreditamos que, embora não se tenha esgotado o assunto, os resultados desta investigação reforçam a importância de ações para o esclarecimento dos estudantes de nível médio acerca da profissão, o mercado de trabalho e o campo de atuação do enfermeiro. Desta forma, estaríamos contribuindo para estimular o interesse pela Enfermagem entre os jovens mais conscientes, informados e esclarecidos. Assim, embora o estudo apresente resultados significativos tem como limitação retratar a visão dos estudantes de uma instituição pública estadual com características peculiares, como a adoção do sistema de cotas, sendo oportuno que fosse replicado em demais instituições de ensino superior. 


\section{REFERÊNCIAS}

1. Lima MJ. O que é Enfermagem? Cogitare Enferm 2005; 10(1):71-4.

2. Souza ACC, Muniz Filha MJM, Silva LF, Monteiro ARM, Fialho AVM. Formação do enfermeiro para o cuidado: reflexões da prática profissional. Rev Bras Enferm 2006;59 (6):805-7.

3. Ojeda BS, Creutzberg M, Feoli AMP, Melo DS, Corbellini VL. Acadêmicos de Enfermagem, nutrição e fisioterapia: a escolha profissional. Rev Latino-Am. Enfermagem 2009; 17(3):396-402.

4. Spindola T, Martins ERC, Francisco MTR. Enfermagem como opção- perfil de graduandos de duas instituições de ensino. Rev Bras Enferm 2008;61(2):164-9.

5. Oguisso T, Lira OS, Vieira APM, Pereira KCM, Mesquita MMC, Silva PJP. Perfil do estudante ingressante no curso de graduação da escola de Enfermagem da universidade de São Paulo. Rev Paul Enferm 2006;25(2):109-16.

6. Val LF, Sá FFMF, Santos RM. Percepção dos alunos de graduação em Enfermagem sobre ser enfermeiro. Nursing 2004;7(76):29-33.

7. Medina NVJ, Takahashi RT. A busca da graduação em Enfermagem como opção dos técnicos e auxiliares de Enfermagem. Rev Esc Enferm USP 2003;37(4):101-8.

8. Kemmer LF, Silva MJP. Como escolher o que não se conhece? Um estudo da imagem do enfermeiro por alunos do ensino médio. Acta paul. enferm. 2007;20(2):125-30.

9. Spindola T, Martins, ERC. Afinal, o que é ser um enfermeiro - falando de nós para vocês. Rev. enferm. UERJ 2002;10(1):62-4.

10. Luchesi LB, Santos CB. Enfermagem: o que esta profissão significa para adolescentes: uma primeira abordagem. Rev Latino-Am. Enfermagem 2005;13(2):158-64.

11. Spindola T, Seibert SL, Francisco MTR, Clós AC. A visão dos alunos do ensino médio acerca do que é ser enfermeiro. R Enferm UERJ 2005;13(3):361-6.

12. Spindola T; Moreira A. O aluno e a Enfermagem: por que esta opção profissional? Esc Anna Nery Rev Enferm 1999;3(3):25-36.

13. Ojeda BS, Eidt OR, Canabarro S, Corbellini VL, Creutzberg M. Saberes e verdades acerca da Enfermagem: discursos de alunos ingressantes. Rev Bras Enferm 2008;61(1):78-84 .

14. Erdmann AL, Fernandes JV, Melo C, Carvalho BR, Menezes
Q, Freitas R, et al. A visibilidade da profissão de enfermeiro: reconhecendo conquistas e lacunas. Rev Bras Enferm 2009;62(4):637-43.

15. Sales SM, Gregório VRN, Andrade MS. O que é ser enfermeiro? Uma visão dos alunos do ciclo básico de Enfermagem. Nursing 2010;14(149):512-7.

16. Polit DF, Beck CT, Hungler BP. Fundamentos de Pesquisa em Enfermagem - métodos, avaliação e utilização. 5ed. Porto Alegre (RS): ArtMed; 2004.

17. Bardin L. Análise de conteúdo. Tradução de Luis Antero Reto e Augusto Pinheiro. São Paulo: Edições 70/Livraria Martins Fontes; 2007.

18. Pai DD, Schrank G, Pedro ENR. O enfermeiro como ser sócio-político: refletindo a visibilidade da profissão do cuidado. Acta paul. enferm. 2006;19(1):82-7.

19. Nauderer TM, Lima MADS. Imagem da enfermeira: revisão da literatura. Rev Bras Enferm 2005;58(1):74-7.

20. Kemmer LF, Silva MJP. A visibilidade do enfermeiro segundo a percepção dos profissionais de comunicação. Rev Latino-Am. Enfermagem 2007;15(2):191-98.

21. Nightingale F. Notas sobre Enfermagem. São Paulo: Cortez; 1989.

22. Scherer ZAP, Scherer EA, Carvalho AMP. Reflexões sobre o ensino da Enfermagem e os primeiros contatos do aluno com a profissão. Rev Latino-Am. Enfermagem 2006;14(2):285-91.

23. Lima RCD, Oliveira ERA, Cade NV, Rabello ML, Santana LG. O processo de cuidar na Enfermagem - mudanças e tendências no mundo do trabalho. Cogitare Enferm 200;10(2):63-67.

24. Trezza MCAF, Santos RM, Leite JL. Enfermagem como prática social: um exercício de reflexão. Rev Bras Enferm 2008;61(6):904-8.

25. Matos E, Pires D. Teorias administrativas e organização do trabalho: de Taylor aos dias atuais, influências no setor saúde e na Enfermagem. Texto Contexto Enferm 2006;15(3):508-14.

26. Hausmann M, Peduzzi M. Articulação entre as dimensões gerencial e assistencial do processo de trabalho do enfermeiro. Texto Contexto Enferm 2009;18(2):258-65.

27. Andrade AC. A Enfermagem não é mais uma profissão submissa. Rev Bras Enferm. 2007;60(1):96-8. 